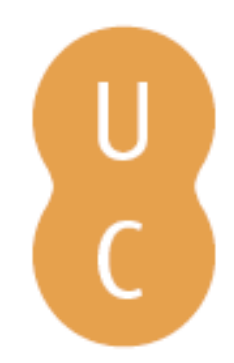

\title{
pommalina
}

\section{Motivos clássicos na poesia novilatina em Portugal: Manuel da Costa}

\author{
Autor(es): $\quad$ Pereira, Susana Marques
}

Publicado por: Imprensa da Universidade de Coimbra

URL

persistente: URI:http://hdl.handle.net/10316.2/37043

DOI: $\quad$ DOI:http://dx.doi.org/10.14195/978-989-26-1043-6_8

Accessed : $\quad$ 26-Apr-2023 02:25:57

A navegação consulta e descarregamento dos títulos inseridos nas Bibliotecas Digitais UC Digitalis, UC Pombalina e UC Impactum, pressupõem a aceitação plena e sem reservas dos Termos e Condições de Uso destas Bibliotecas Digitais, disponíveis em https://digitalis.uc.pt/pt-pt/termos.

Conforme exposto nos referidos Termos e Condições de Uso, o descarregamento de títulos de acesso restrito requer uma licença válida de autorização devendo o utilizador aceder ao(s) documento(s) a partir de um endereço de IP da instituição detentora da supramencionada licença.

Ao utilizador é apenas permitido o descarregamento para uso pessoal, pelo que o emprego do(s) título(s) descarregado(s) para outro fim, designadamente comercial, carece de autorização do respetivo autor ou editor da obra.

Na medida em que todas as obras da UC Digitalis se encontram protegidas pelo Código do Direito de Autor e Direitos Conexos e demais legislação aplicável, toda a cópia, parcial ou total, deste documento, nos casos em que é legalmente admitida, deverá conter ou fazer-se acompanhar por este aviso. 
politica no Brasil do sécu

Categorias aristotélicas por Silvestre Pinheiro Ferreira - Musas errantes: tesouros da Antiguidade Clássica no labirinto da Biblioteca Nacional Brasileira - Eudoro de Sousa e a Mitologia • Câmara Cascudo em defesa de Epicuro - Medéia carioca - Ecos de Platão em Vergílio Ferreira - Imaginário clássico na poesia de António Arnaut - Motivos clássicos na poesia novilatina em Portugal: Manuel da Costa - Uma Ifigénia portuguesa: "Noite escura" de João Canijo • Uma leitura de Mau Tempo no Canal de Vitorino Nemésio $\bullet A$ phýsis grega e o Brasil: as viagens de Von Martius $\bullet$ Fantasia para dois coronéis e uma piscina. Ecos clássicos num contexto do séc. XX

\section{A RECEPÇÃO DOS CLÁSSICOS EM PORTUGAL E NO BRASIL}

Maria de Fátima Silva Maria das Graças de Moraes Augusto COORDENAÇÃo 


\section{SÉRIE MITO E (RE)ESCRITA}

ISSN: $2182-8814$

\section{PERIODICIDADE: Anual}

Apresentação: Poetas, pintores, escultores, na Antiguidade, familiarizados com mitos antigos de deuses e de homens, que cristalizavam experiências, interrogaçóes, respostas quanto à existência do homem no tempo e no mundo, em mitos se inspiraram, em contínua criação-recriaçẩo, para neles verterem a sua própria experiência temporal, com todos os desassossegos e inquietaçóes, com todo o espanto, horror ou encantamento pela excecionalidade da ação humana, que rasga ou ilumina fronteiras de finitude. Esses percursos da criação merecem, hoje, a atenção e análise dos Estudos Literários e, como não podia deixar de ser, dos Estudos Clássicos, muito peculiarmente. Importa, pois, proceder à publicação sistemática de estudos deste cariz, que se destaquem pela qualidade científica e pela originalidade, sendo dedicados, sobretudo, a autores de língua portuguesa. Assim se dá corpo à linha editorial MITO E (RE)ESCRITA.

Este livro, realizado no âmbito do Convénio de Cooperação Académica entre o CECH - Centro de Estudos Clássicos e Humanísticos da UC - e o PRAGMA - Programa de Estudos de Filosofia Antiga da UFRJ -, reúne um conjunto de estudos sobre a recepçáo de temas e modelos greco-latinos na literatura e cultura de Portugal e Brasil.

A sua originalidade resulta da participação de diferentes culturas e das especialidades académicas diversas dos investigadores que nele participam, provenientes da Literatura, da Filosofia e da História Antiga. O lapso de tempo abrangido, que vai do séc. XVI ao XX, permite uma visáo de conjunto da evoluçáo operada no perfil cultural de ambos os países e na definição de um trajeto em boa parte comum. 


\section{Motivos clássicos na poesia novilatina em Portugal - Manuel da Costa}

(Classical motives in neo-Latin poetry in Portugal: Manuel da Costa)

Susana Marques Pereira

Universidade de Coimbra

(marquessusana@vizzavi.pt) 
Página deixada propositadamente em branco 
Resumo - Como toda a produção neolatina desta época, profundamente influenciada, quer no estilo, quer nas ideias, pelos autores clássicos, os motivos da Antiguidade são múltiplos nas composiçôes de Costa, desde logo no próprio formato e no metro escolhido. Assim o epitalâmio, em hexâmetros elogiosos para os noivos e para as famílias respetivas: distingue-lhes as qualidades físicas e intelectuais, bem como a dignidade dos seus comportamentos e atitudes.

Palavras Chave - Renascimento português, epitalâmio, Manuel da Costa

Abstract - As all the neo-Latin production of sixteenth century literature, deeply influenced, in style as in ideas, by the classical authors, Manuel da Costa integrates a lot of conventions from Antiquity in his compositions. Epithalamion, a celebration of weddings and of the families involved in, underlines their physical as well as intellectual qualities, as well as the dignity of their behaviour and attitude.

Keywords - Portuguese Renaissance, epithalamion, Manuel da Costa

A matriz clássica consubstancia-se numa assimilação e numa (re)apropriação multilingue, multiforme, intemporal e universal, como se sabe. A história, a literatura, a língua, o teatro, a filosofia, a mitologia, a arte, a arquitetura, a matemática, a astronomia, a medicina, o direito, a política testemunham a amplitude e a diversidade de domínios influenciados pelo legado da Antiguidade, em espaços e épocas diferenciados. Permeável a sensibilidades, experiências, identidades e contextos variados, a tradição clássica, raiz histórica e cultural, converte-se em manancial de inspiração e de imitação reiteradas, numa revitalização contínua e propiciadora de sentidos renovados.

O humanismo renascentista constituiu um momento de excelência para evidenciar a importância da cultura da Antiguidade também em Portugal, sob formas clássicas de epigramas, odes, longos poemas heróicos ou epitalâmios, por exemplo - "a velha escolástica desmorona e as diuinae litterae dão lugar às humanae litterae como ideal de vida e de cultura, refratando-se em novo meio o eixo teocêntrico em que girava tudo o que ao homem concernia e que doravante assume primado absoluto. (...)

No afã de ressuscitar valores e gostos, da Antiguidade clássica advêm luzes e espelhos, bem como os instrumentos de implantação da nova ordem de viver e de sentir" ${ }^{2}$.

$\mathrm{Na}$ época áurea dos Descobrimentos portugueses, o confronto com o paradigma de outrora, elogioso para os Lusitanos, favorecia a divulgação e

1 Cf. e. g. André 1991-1992: 223 sqq.; Ramalho 1998.

2 Mendes 1991-1992: 412. 
o panegírico da nossa expansão, bem como a celebração das figuras que a proporcionaram e da grandeza do 'peito ilustre lusitano'3 em geral. $\mathrm{O}$ ambiente de epopeia experimentado no país num momento de prosperidade ${ }^{4}$ ganhou forma expressiva n' Os Lusíadas, obra representativa de uma atitude laudatória usual nos autores de Quinhentos ${ }^{5}$, com voz noutros nomes para além de Camóes, ora em português (cf. e. g. António Ferreira, João de Barros), ora em latim (cf. e. g. Diogo de Teive, Inácio de Morais), a língua internacional da época.

O convívio frequente entre humanistas de toda a Europa propiciava a difusão dos feitos portugueses a uma escala alargada - numa valorização evidente dos Lusitanos, que davam a conhecer ao mundo novas terras e novas gentes, os nossos conterrâneos não se poupavam a esforços para fazer cessar 'tudo o que a Musa antiga canta $<$ va $>/$ que outro valor mais alto se alevanta $<$ va $>^{\text {'6 }}$.

Manuel da Costa, jurista de renome e poeta novilatino ${ }^{7}$, fez jus ao espírito do tempo nos dois epitalâmios de tema nacional e contemporâneo que escreveu em latim: em tom encomiástico, cantou as núpcias do infante D. Duarte com D. Isabel de Bragança, em 1552, e um ano depois, o matrimónio do príncipe João, herdeiro de D. João III, com a princesa Joana de Castela.

"Como toda a produção neolatina desta época (...), profundamente influenciada, quer no estilo, quer nas ideias, pelos autores clássicos e em especial latinos"8, os motivos da Antiguidade são múltiplos em ambas as composiçóes de Costa, desde logo no próprio formato e no metro escolhido: o epitalâmio, género cultivado já por autores da Antiguidade como Safo, Teócrito, Catulo, Claudiano ou Estácio, em hexâmetros elogiosos para os noivos e para as famílias respetivas, distinguindo-se qualidades físicas e

3 Camões, Os Lusíadas 1.3.5.

4 A este propósito, cf. e. g. Matos 1984; André 1991-1992: 218 sqq.

5 Como observa Ramalho 1998: 23, a exaltação de personagens ilustres na literatura "era uma prática a que os humanistas se prestavam, na busca de proteçáo e de honras materiais".

6 Cf. Camões, Os Lusíadas 1.3.7-8. Ramalho 1998: 36 salienta precisamente que "a referência aos Gregos e aos Romanos para valorizar os Portugueses vai ser repetida depois na literatura em Portugal do século XVI até cristalizar nos versos de Os Lusíadas". Sobre a importância concedida à influência da Roma antiga em particular n' Os Lusíadas, obra em que os Portugueses são "frequentemente comparados aos povos da Antiguidade, imagética mítico apoteótica do Renascimento", cf. Rodrigues 1999: 183-218.

7 Outros juristas portugueses do Renascimento aliaram o Direito ao cultivo das Letras, como Pedro Sanches, Miguel e António de Cabedo (cf. Ramalho 1988: 187).

8 Soares 2010: 81. 
intelectuais dos mesmos, bem como a dignidade dos seus comportamentos e atitudes?.

A presente reflexão ocupa-se do Carme heróico sobre as núpcias de João e Joana, serenissimos principes da Lusitânia, também conhecido como Proteu: o enlace do único filho sobrevivente de D. João III e de D. Catarina, vital para assegurar a sucessão dinástica portuguesa e a independência da nação, difundia por todo o reino uma tonalidade de alegria e de esperança, cantada igualmente por outros poetas quinhentistas, como Diogo de Teive ou António Ferreira ${ }^{10}$ - o júbilo contagiava os Lusitanos em geral, em particular pelas implicações políticas que o casamento assumia para a pátria ${ }^{11}$. Como é sabido, as alianças matrimoniais entre a Casa Real Portuguesa e a corte castelhana revelaram-se estratégicas para estreitar laços e para garantir a paz entre os reinos peninsulares, durante a soberania de D. Manuel I e de D. João III.

Poema de assunto histórico e de natureza claramente celebrativa, o carme de Manuel da Costa recorre com frequência à comparação dos Portugueses e dos vizinhos Castelhanos com divindades, heróis e povos da Antiguidade, procedimento muito comum no Renascimento, como ficou dito, e também nos epitalâmios - o paralelo com referentes singulares, por norma excedidos pelos homens de Quinhentos, engrandece os contemporâneos de Costa, poeta áulico e distinto conhecedor da arte da eloquência, e proporciona-lhe a exibição de uma erudição inspirada em modelos greco-latinos, muito valorizada na época.

Para lá dos nomes tradicionais associados à composição de epitalâmios na Antiguidade, os Poemas Homéricos, Hesíodo, Eurípides, Virgílio são decerto textos/ autores que o poeta novilatino conhecia, no original ou em tradução ${ }^{12}$, e de que se serviu para escrever os seus carmes (cf. e.g. imitatio dos versos $387-$ 389 do canto IV das Geórgicas, nos primeiros quatro versos do poema, ou do verso 518 do canto VII da Eneida, no verso 155; alusão a episódios como o encontro de Nausícaa e Ulisses na ilha dos Feaces, ou a retenção da armada grega em Áulide devido à ausência de ventos para navegar).

9 Sobre a evolução do epitalâmio desde a Antiguidade, cf. Sánchez-Marín 1992: 200-201.

10 Cf. Diogo de Teive, oração e carme em honra deste matrimónio; António Ferreira, écloga Arquigâmia, soneto 2.17, ode 1.2.

11 A propósito do amor destes príncipes, reiteradamente cantado pelos autores de Quinhentos, cf. Soares 2010: 291, n. 101. Sobre a realização do casamento, cf. Andrade 1976, cap. 95.

12 A propósito da difusão dos clássicos na Europa no século XVI, cf. Rodrigues 1999: 212, bem como as referências bibliográficas aí sugeridas. 
A seleção específica dos motivos clássicos presentes no poema permite pressagiar felicidade para os nubentes, delinear referências geográficas, explicitar a origem de topónimos, mencionar notaçóes cronológicas, caraterizar a governação do monarca reinante, comparar divindades e heróis da Antiguidade a personagens ilustres da época, estabelecer paralelos entre situações de outrora e do século XVI, ou ainda traduzir estados de alma.

$\mathrm{O}$ relato dos festejos celebrativos do matrimónio dos príncipes João e Joana é auspiciosamente colocado na boca do divino Proteu, na parte inicial do poema - a famosa capacidade profética daquele deus marinho e polimórfico sugere um cenário venturoso para noivos tão distintos, descendentes de ilustres famílias, e para núpcias tão esplendorosas ${ }^{13}$.

A narração de Proteu surge em resposta à curiosidade das Nereides face ao tumulto experimentado no mar dos Cárpatos: um magnífico cortejo divino se apresta rumo ao Ocidente. A comitiva congrega prestigiosamente divindades do amor, por natureza associadas à celebraçáo de epitalâmios, como Vénus, Cupido e Himeneu, e deuses marinhos, de que se destacam Neptuno e Tritão, cuja presença honrosa remete para a identidade marinheira dos Portugueses e para a prosperidade resultante da expansão marítima lusitana e, por outro lado, evoca uma fecundidade almejada para o trono nacional, simbolizada na água, fonte de vida e de fertilidade. A cooperação de divindades representativas de diferentes domínios expressa o patrocínio generalizado do mundo supra-humano ao casamento real celebrado ${ }^{14}$.

A referência genérica ao local de destino do cortejo, 'as costas de Febo cadente', permite a alusão ao trajeto diário daquela divindade, que percorria o céu num magnífico carro puxado por cavalos, desde o Oriente até ao seu declínio no Ocidente, episódio ilustrativo da visão geocêntrica do universo, comum no século XVI. O recurso à mitologia clássica para delimitar a geografia é reincidente no poema, proporcionando a exibiçáo da cultura de Manuel da Costa, como convinha. Assim acontece a propósito da menção mais precisa ao espaço luso onde decorriam as grandiosas festividades, Lisboa, designada como 'a cidade que recebeu de Ulisses o nome', numa perífrase elucidativa da etimologia do topónimo da capital portuguesa. Lisboa

13 Malogradamente, porém, a alegria destas núpcias seria contraposta por uma dor profunda, como é sabido, já que cerca de um ano depois, a 2 de janeiro de 1554, o príncipe viria a falecer, deixando a esposa grávida de um filho, D. Sebastião. Sobre o tratamento do tema da morte de D. João na poesia quinhentista, cf. Soares 2010.

14 António Ferreira, na écloga Arquigâmia, evidencia também a presença prestigiosa das divindades do Olimpo na chegada de D. Joana a Lisboa, para casar com o príncipe herdeiro da coroa portuguesa. 
é ainda reclamada, mais adiante, como 'a cidade de Marte', seja porque a chegada da noiva oriunda de Castela à urbe portuguesa é aclamada ao som de disparos de canhóes, numa toada evocativa da guerra, apanágio de Marte, e na qual os Portugueses se distinguiram, seja também pelo facto de as nossas armadas partirem de Lisboa para as suas conquistas e descobertas.

A erudição etimológica e mítica do poeta revela-se ainda na identificação da lusitana pátria como 'o reino de Luso', origem que Camôes confirma n' Os Lusiadas 3.21.5-7:

"Esta foi a Lusitânia, derivada
de Luso ou Lisa, que de Baco antigo
filhos foram, parece, ou companheiros ${ }^{15}$.

A natureza associa-se sintomaticamente à alegria da ocasiáo, como era hábito nos epitalâmios, presenteando os noivos com um tempo bonito e luminoso. O poeta novilatino expressa estas notaçóes cronológicas através da menção a Láquesis, que tece o dia de um branco propício, evocativo da pureza $^{16}$, como em Catulo 64, 350 sqq., e ao Titá Sol, o qual concede a sua luz radiante à jornada ditosa que unirá os jovens noivos.

A travessia do Tejo, de Lisboa ao Barreiro, por D. João III, ao encontro da princesa que chega do reino vizinho, destinada a seu filho, João, produz o momento oportuno para enquadrar o governo do monarca reinante na Idade de Ouro, procedimento comum entre os humanistas de Quinhentos, evocativo da criaçáo hesiódica do mito das cinco idades, temática que teve um tratamento amplo ao longo dos tempos, como se sabe ${ }^{17}$. A justiça e a observância da lei são as caraterísticas que Costa elege para colocar panegiricamente D. João III como o introdutor daquela idade preciosa no reino de Luso, destacando-o como um bom rei, como uma figura paradigmática para o seu povo, que se impunha pelas suas virtudes e pela sua excelência ${ }^{18}$. De resto, a dignidade do soberano português é ainda sublinhada por uma imagem retirada da natureza: a presença e a autoridade de D. João III instigam o ar tempestuoso a serenar, sendo apenas

15 Sobre a origem da palavra 'Lusíadas', cf. Ramalho 1983: 221-236.

16 A propósito da simbologia da cor branca, cf. Chevalier e Gheerbrant 1982: 128130, s. v. 'branco'.

17 A este propósito, cf. Soares 2010: 268-269.

18 Sobre o conceito de realeza e a imagem do bom rei, tema que constitui um lugarcomum, cf. Soares 2010: 100-108; Beau 1957: 176-221. 
permitida uma suave brisa ao Zéfiro, que coopera de modo agradável na breve viagem a caminho de um destino que se deseja de amor e de felicidade.

Diversas figuras eminentes acompanham D. João III até à outra margem do Tejo, percurso que o poeta novilatino aproveita para, com intuito laudatório, aproximar Lourenço Pires de Távora, designado como procurador do príncipe Joáo para tratar do seu enlace com D. Joana de Castela, de um modelo do passado, o herói Tideu, pai de Diomedes e outrora enviado a Tebas com o propósito de convencer Etéocles a permitir que Polinices tomasse o governo do reino. Para além de ambos serem incumbidos de missóes diplomáticas, Lourenço Pires de Távora, personagem coeva de Costa, distinguiu-se de modo particular pelo seu valor militar no norte de África ${ }^{19}$, e os seus feitos são apresentados como mais notáveis do que os do ilustre Tideu, que aniquilara inúmeros Tebanos, evidenciando a superioridade portuguesa no que ao mérito guerreiro diz respeito (o mesmo sentimento é destacado por Camóes n' $O s$ Lusíadas - cf. as razóes evocadas por Vénus e por Marte para que se apoiassem os Portugueses no episódio do consílio dos deuses no Olimpo, no canto I).

O regresso da comitiva a Lisboa, com D. Joana a bordo, ocasiona o retardado encómio da noiva, cuja singular beleza física é comparada à de figuras míticas, como é próprio dos epitalâmios: a jovem princesa Nausícaa e a nereide Tétis são as personagens escolhidas para o paralelo estabelecido, porquanto os episódios que protagonizam, associados ao tema do encontro e do amor, ocorrem em ambientes situados junto à água. A individualidade da noiva castelhana, cuja excelência Manuel da Costa pretende exaltar, dispensa a menção ao elemento masculino que completa o par de forma explícita no mito, respetivamente Ulisses e Peleu. Na senda do tom encomiástico habitual na poesia quinhentista, a formosura de D. Joana suplanta a das demais figuras femininas.

$\mathrm{Na}$ trajetória efetuada no Tejo, surge a oportunidade para uma menção breve ao séquito feminino que acompanhava a nubente, realçando-se de modo genérico os atrativos físicos das acompanhantes de D. Joana, enaltecidas ao serem identificadas como Ninfas.

A sumptuosidade da armada que conduzia a noiva a Lisboa, expressiva da prosperidade vivida no reino na época dos Descobrimentos, convida a recordar a imensa e poderosa frota grega outrora retida em Áulide ${ }^{20}$ : elogiosamente, os barcos lusitanos superam os helénicos, no aparato e em número.

19 A propósito da biografia de Lourenço Pires de Távora, cf. Machado 1752, t. III; Caetano de Sousa 1950, t. IV; Sousa 1938: 290-293.

20

Cf. Eurípides, Ifigénia em Aulide, 231-302. 
A exaltação da família real da noiva não é esquecida, na insigne figura de Carlos V, seu pai, pelas conquistas que obteve. Os feitos do soberano de Castela são laudatoriamente comparados a um exemplum da história de Roma antiga, César Augusto, conquistador paradigmático, com o qual Carlos V é identificado, embora desta feita Manuel da Costa se esquive a afirmar que o chefe do reino vizinho ultrapassou os heróis da Antiguidade, ao contrário do que faz de forma reiterada ao longo do carme em relação aos Portugueses seus conterrâneos.

Entrecruzando passado próximo e circunstâncias presentes, o poema faz uso de um processo épico já usado nos Poemas Homéricos (cf. Il. 18. 478 sqq.), a descrição de acontecimentos por meio de objetos: na verdade, saindo das profundezas douradas $<$ do Tejo $>$, as Náiades trazem como presente uma colcha nupcial, tecida para uso do leito de Joana, para que se possa ver Afonso Henriques e, por ordem, os reis lusitanos, ascendentes de sua mãe (136-140). De modo oportuno - e laudatório -, o puluinar geniale oferecido à noiva, evocativo do concedido outrora à divina Tétis (cf. Cat. 64, 47 sqq.), mostra cenas referentes à história de Portugal, desde D. Afonso Henriques. Arguto, Manuel da Costa, a quem chamavam doctor subtilis, descreve com particular detalhe o nascimento extraordinário do monarca reinante, D. João III, aludindo à auspiciosa intervenção divina no parto do mesmo. As divindades que assistem à sua vinda ao mundo ilustram caraterísticas definidoras do seu reinado, prenunciando-lhe felicidade: a Paz, Astreia, deusa da justiça, e as Musas, alusivas à proteção que o monarca concedeu às Letras.

A chegada da noiva a Lisboa permite ao poeta passar para um cenário interior, mais íntimo e propício à expressáo de sentimentos e emoçóes, o palácio, onde o príncipe João aguarda a noiva com ansiedade, junto de sua mãe, a rainha D. Catarina. Naturalmente, Manuel da Costa louva ambas as figuras, selecionando de modo significativo a divina Anfitrite para o confronto que estabelece entre a beleza e os dotes de alma daquela e os da esposa de D. João III - como Anfitrite é senhora do mar, assim também D. Catarina era soberana de um povo de ilustres marinheiros e de um país que abria ao mundo novas paragens e culturas, a partir do Tejo; os papéis de mãe e de rainha entrelaçam-se, mesclando os domínios pessoal e público.

O louvor das virtudes do príncipe herdeiro, por seu turno, converteu-se em matéria cantada por diversos autores quinhentistas ${ }^{21}$ - no Proteu, porém, referem-se de modo genérico aquelas que refletem qualidades paternas

21 A este propósito, cf. Soares 2010: 47-50, 279. 
(dignidade, majestade), para se descrever em seguida o estado de alma de D. João, noivo ansioso pela chegada da jovem princesa.

A derradeira menção a motivos inspirados na Antiguidade clássica ajusta-se de modo harmonioso ao tema do carme, quer porque alude a um enlace expressivo da fusão natural entre o Sol e a Luz que ele encerra e com a qual ilumina o mundo, quer também porque confere uma tonalidade luminosa ao final do poema, pela comparação do ânimo de D. João, cuja amada se aproxima, com o do Sol radioso, prestes a desposar a chama da $\mathrm{Luz}^{22}$. Tal casamento no domínio mítico é prestigiosamente conduzido pelo "auspicioso pai omnipotente e por Juno prónuba", deuses cujos epítetos "permitem ao autor aludir a dois ritos do matrimónio romano, que costumam aparecer no epitalâmio clássico: o sacrifício augural inicial, em que se tomavam os auspícios para a nova união (cf. St., S. 229), e a assistência da pronuba ou matrona à noiva, especialmente unindo a sua dextra à do noivo (St., S. 239)", como bem notou Sánchez Marín 1992: 212.

Neste ambiente cintilante, prenunciador de bom augúrio para o futuro da pátria lusa e da coroa portuguesa, Proteu podia recolher-se com tranquilidade à sua morada, terminada a narração, pois no mar dos Cárpatos já anoitecera, embora os raios da Lua conferissem brilho e claridade ao meio envolvente.

Numa época em que a cultura e a civilização clássicas são sobremodo valorizadas na Europa em geral, enquanto modelos a igualar ou mesmo a ultrapassar, a diversos níveis, os autores portugueses de Quinhentos destacam os conterrâneos, agentes de uma prosperidade sustentada pelo governo justo dos seus soberanos ${ }^{23}$. Neste enquadramento se posiciona Manuel da Costa que, recuperando episódios e figuras do mito e da história antigos, exibe os seus conhecimentos e testemunha a relevância da matriz clássica na sua época.

22 O confronto entre o Sol, gerador de clareza e de luminosidade, e o bom rei surge noutros autores de Quinhentos: cf. Soares 2010: 100-101, 298.

23 Ilustra no entanto André 1991-1992: 233 sqq. como, a par do encómio frequente de múltiplos autores da época, se notava também com alguma insistência uma crítica, mesmo que velada, a aspetos negativos da expansáo ultramarina portuguesa, porque "o poder corrompe, a fama ofusca, a riqueza cega. Sabiam-no os Gregos, que apelavam constantemente à moderação. Não o respeitaram os Romanos que trilharam o caminho da degradação até à queda do império" (idem, ibidem: 233). 


\section{Bibliografia}

Andrade, F. (1976, reimpr.), Crónica de D. João III. Introd. e rev. de Almeida, M. Lopes. Porto: Lello Editores.

André, C. (1991-1992). "Luz e penumbra na literatura humanista dos Descobrimentos", Humanitas 43-44: 217-256.

Beau, A. E. (1957), “A realeza na poesia medieval e renascentista portuguesa-II,”, Boletim de Filologia 16. 3-4: 176-221.

Chevalier, J., Gheerbrant, A. (1994), Dicionário dos símbolos - mitos, sonhos, costumes, gestos, formas, figuras, cores, números. Trad. de Rodriguez, C., Guerra, A. Lisboa: Teorema.

Machado, D. B. (1752), Biblioteca Lusitana. III. Lisboa: Atlântida editora.

Marques, S. (2005), Dois epitalâmios latinos de Manuel da Costa (século XVI). Introdução. Tradução. Notas e comentários. Coimbra: Instituto de Estudos Clássicos, FLUC.

Matos, L. (1991), L'expansion portugaise dans la littérature latine de la Renaissance. Pref. de J. Pina Martins. Lisboa: Fundação Calouste Gulbenkian.

Mendes, J. P. (1991-1992), "Homo rhetoricus: retórica e Descobrimentos”, Humanitas 43-44: 411-423.

Miguel Mora, C. (1999), “As leituras dos humanistas: fontes secundárias de Manuel da Costa”, Ágora. Estudos Clássicos em Debate 1: 133-154.

- 1999. Raizes greco-latinas da cultura portuguesa. Acta do I Congresso da APEC. Coimbra: Classica Digitalia.

Ramalho, A. C. (1983), Estudos sobre o século XVI. Lisboa: INCM.

Ramalho, A. C. (1988-2000), Para a história do humanismo em Portugal: I (Coimbra, 1988); II (Lisboa, 1994); III (Lisboa, 1998); IV (Lisboa, 2000).

Rodrigues, N. S. (1999), “Camões e a história da Roma antiga”, in Raizes greco-latinas da cultura portuguesa: $183-218$

Sánchez-Marín, J. A. (1991-1992), “Caracteristicas de la obra poética de Manuel da Costa”, Humanitas 43-44: 257-274.

Sánchez-Marín, J. A. (1992), "Un epitalamio latino: el carmen Proteus de Manuel da Costa", in Miscelânea de estudos em honra do Prof. A. Costa Ramalho. Coimbra, INIC: 199-213.

Soares, N. N. C. (2010, $3^{\mathrm{a}}$ ed.), Diogo de Teive. Tragédia do príncipe João. Coimbra: $\mathrm{CECH}$. 
Sousa, A. C. (1950), Provas da história genealógica da Casa Real portuguesa. IV. Coimbra: Atlântida.

Sousa, Frei L. (1938), Anais de D. João III. Prefácio e notas de Lapa, M. Rodrigues. Lisboa: Sá da Costa.

\section{Nota final}

Este trabalho corresponde, em parte, ao apresentado no Congresso Internacional $O$ melhor de tudo é a água. Real e simbólico: da Antiguidade aos nossos dias (Coimbra, 7-8 de março de 2013). 
Maria de Fátima Sousa e Silva é Professora Catedrática do Instituto de Estudos Clássicos da Universidade de Coimbra. Desenvolveu, como tese de doutoramento, um estudo sobre a Comédia Grega Antiga (Crítica do teatro na Comédia Grega Antiga), e, desde então, tem prosseguido com investigação nessa área. Publicou já traduções comentadas de nove comédias de Aristófanes, além de um volume com a tradução das peças e dos fragmentos mais significativos de Menandro.

Maria das Graças de Moraes Augusto é Professora Titular no Departamento de Filosofia do Instituto de Filosofia e de Ciências Sociais da Universidade Federal do Rio de Janeiro (UFRJ). A sua investigação sobre História da Filosofia Antiga abrange temas como Platão e a herança platónica, filosofia e conhecimento no pensamento antigo, filosofia e literatura na tradição antiga e recepção dos clássicos gregos no Brasil.

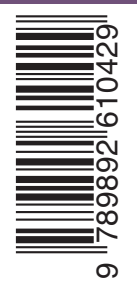


OBRA PUBLICADA

COM A COORDENAÇĀO

CIENTÍFICA
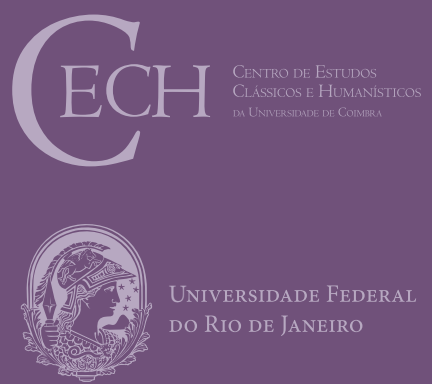

- U 